\title{
Studies of very preterm adults with bronchopulmonary dysplasia are relevant for today's graduates -invited response to editorial commentary
}

\author{
Brian A. Darlow ${ }^{1}$, Jun Yang ${ }^{2}$ \\ ${ }^{1}$ Department of Paediatrics, University of Otago, Christchurch, New Zealand; ${ }^{2}$ Respiratory Physiology Laboratory, Christchurch Hospital, \\ Canterbury District Health Board, New Zealand \\ Correspondence to: Professor Brian A. Darlow. Department of Paediatrics, University of Otago, PO Box 4345, Christchurch 8140, New Zealand. \\ Email: brian.darlow@otago.ac.nz. \\ Provenance and Peer Review: This article was commissioned by the editorial office, Translational Pediatrics. This article did not undergo external peer review. \\ Response to: Chen IL, Chen HL. Lung function in adults born prematurely with bronchopulmonary dysplasia. Transl Pediatr 2020. doi: 10.21037/tp- \\ 20-116
}

Submitted Apr 28, 2020. Accepted for publication May 11, 2020.

doi: $10.21037 / \mathrm{tp}-20-132$

View this article at: http://dx.doi.org/10.21037/tp-20-132

We are grateful for the opportunity to comment briefly on the Editorial by Chen and Chen on our recent publication on static lung function in very low birth weight adults (1).

As the Editorial notes there has been a wealth of data on respiratory outcome and function of very low birthweight $(\mathrm{VLBW} ;<1,500 \mathrm{~g})$ and very preterm (VP; $<32$ weeks gestation) infants in childhood and adolescence but much less data on outcome in young adults. Overall, there are relatively few studies of VP/VLBW adults published from population-based cohorts, which are required to avoid the biases inherent in hospital and opportunistic followup studies. The majority of these studies have focused on spirometry with very few assessing other aspects of lung function (2).

In our population-based study of VLBW young adults assessed at a mean 28.4 years we found that compared with term born controls, VLBW survivors showed a higher incidence of airflow obstruction, gas trapping, reduced gas exchange and increased ventilatory inhomogeneity. Within the VLBW cohort, those who had been diagnosed with bronchopulmonary dysplasia (BPD) had further reduced airflow, increased gas trapping and ventilatory inhomogeneity compared with those without BPD (1).

The Editorial suggests our findings related to young adults born in 1986 might be less relevant for current NICU graduates because of changes in neonatal intensive care practices, particularly those aimed at avoiding or ameliorating the perinatal lung injury that results in BPD. However, we believe our results will remain relevant for contemporary VP/VLBW survivors for a number of reasons.

Although there have been many advances in neonatal practices aimed at prevention of lung injury in VP/VLBW infants in recent years, there is compelling evidence that the incidence of BPD is not decreasing and may even be increasing in many countries. Our definition of BPD was the widely used requirement for supplementary oxygen at 36 weeks post-menstrual age (3) (although the majority would have also required supplementary oxygen for 28 days). Doyle and colleagues reviewed the outcome for all infants born at $<28$ weeks' gestation in Victoria, Australia in three time periods, 1991-1992, 1997 and 2005 (4). Despite an increase in less invasive methods of ventilation over time, the incidence of BPD (defined as in our study) was highest in the latest period. Similarly, Lui and colleagues reported on data from population-based neonatal networks from 11 countries over two epochs, 2007-2011 and 2012-2015; again, the incidence of BPD increased over time in 9 of the 11 networks (5).

Follow-up studies of VP infants born over the past two decades in the surfactant era show significantly lower spirometry values in middle (8 years) (4) and late (9-11 years) (6) childhood compared with controls, as in our study. Doyle and colleagues have also reported that 
extremely preterm (EP) infants had worsening airways obstruction between 8 and 18 years but then no change to 25 years (7). Furthermore, EP graduates with BPD had worse airflows and trajectories than those without (7).

Despite our findings of poorer respiratory function in VLBW adults than controls, it is important to recognise that most of the results were in the usually accepted normal ranges. Given that peak respiratory function is attained in the third decade of life (8), the most important question might be what will be the rate of decline in subsequent years; will it match that of their term born peers or be accelerated even without additional lung insults, such as smoking? Hence, it will be important, not only to replicate the full range of lung function tests we have undertaken in other cohorts of VP/VLBW adults in their 20s to see whether our results are confirmed, but also to follow these cohorts with repeated tests as they age further.

\section{Acknowledgments}

Funding: None.

\section{Footnote}

Conflicts of Interest: Both authors have complete the ICMJE uniform disclosure form (available at http://dx.doi. org/10.21037/tp-20-132). The authors have no conflicts of interest to declare.

Ethical Statement: The authors are accountable for all aspects of the work in ensuring that questions related to the accuracy or integrity of any part of the work are appropriately investigated and resolved.

Open Access Statement: This is an Open Access article distributed in accordance with the Creative Commons Attribution-NonCommercial-NoDerivs 4.0 International License (CC BY-NC-ND 4.0), which permits the non-

Cite this article as: Darlow BA, Yang J. Studies of very preterm adults with bronchopulmonary dysplasia are relevant for today's graduates-invited response to editorial commentary. Transl Lung Cancer Res 2020;9(3):266-267. doi: 10.21037/tp-20-132 commercial replication and distribution of the article with the strict proviso that no changes or edits are made and the original work is properly cited (including links to both the formal publication through the relevant DOI and the license). See: https://creativecommons.org/licenses/by-nc-nd/4.0/

\section{References}

1. Yang J, Kingsford RA, Horwood LJ, et al. Lung function of adults born at very low birth weight. Pediatrics 2020;145:e20192359.

2. Doyle LW, Andersson S, Bush A, et al. Expiratory airflow in late adolescence and early adulthood in individuals born very preterm or with very low birthweight compared with controls born at term or with normal birthweight: a metaanalysis of individual participant data. Lancet Respir Med 2019;7:677-86.

3. Shennan AT, Dunn MS, Ohlsson A, et al. Abnormal pulmonary outcomes in premature infants: Prediction from oxygen requirement in the neonatal period. Pediatrics 1988;62:527-32.

4. Doyle LW, Carse E, Adams AM, et al. Ventilation in extremely preterm infants and respiratory function at 8 years. N Engl J Med 2017;377:329-37.

5. Lui K, Lee SK, Kusuda S, et al. Trends in Outcomes for Neonates Born Very Preterm and Very Low Birth Weight in 11 High-Income Countries. J Pediatr 2019;215:32-40.e14.

6. Simpson SJ, Logie KM, O'Dea CA, et al. Altered lung structure and function in mid-childhood survivors of very preterm birth. Thorax 1988;82:527-32.

7. Doyle LW, Irving L, Haikerwal A, et al. Airway obstruction in young adults born extremely preterm or extremely low birth weight in the postsurfactant era. Thorax 2019;74:1147-53.

8. Gibson AM, Doyle LW. Respiratory outcomes for the tiniest or most immature infants. Semin Fetal Neonatal Med 2014;19:105-11. 